\title{
Combination of photoelectrocatalysis and ozonation: A novel and powerful approach applied in Acid Yellow 1 mineralization
}

\author{
Guilherme Garcia Bessegato, Juliano Carvalho Cardoso, Bianca Ferreira da Silva, \\ Maria Valnice Boldrin Zanoni*
}

Department of Analytical Chemistry, Institute of Chemistry, Universidade Estadual Paulista “Júlio de Mesquita Filho"-UNESP. Av. Prof. Francisco Degni, 55, 14800-060, Araraquara, SP, Brazil

\section{A R T I C L E I N F O}

Article history:

Received 25 February 2015

Received in revised form 27 May 2015

Accepted 9 June 2015

Available online 17 June 2015

Keywords:

Photoelectrocatalytic oxidation

Catalytic ozonation

Dye degradation

Ozone assisted Photoelectrocatalysis

\begin{abstract}
A B S T R A C T
Photoelectrocatalytic oxidation (PEC) is known to be a powerful technique employed with the aim of promoting organic degradation. Its efficiency is nonetheless found to be dramatically decreased when applied in highly concentrated effluent treatment owing to the reduced transparency which minimizes the photons reaching the semiconductor surface. In light of that, the present work seeks to describe a novel combination of photoelectrocatalysis and ozonation $\left(\mathrm{O}_{3}+\mathrm{PEC}\right)$ techniques, aiming at achieving a faster decolorization of a highly concentrated solution and a higher rate of mineralization. The Acid Yellow 1 dye (AY1), widely used in cosmetics was chosen as a colorful solution model. $\mathrm{TiO}_{2}$ nanotubes electrode was used as photoanode in an annular bubble reactor operating at $2.0 \mathrm{~V}$ with UV-B irradiation in the presence of $1.25 \times 10^{-4} \mathrm{~mol} \mathrm{~min}^{-1}$ of $\mathrm{O}_{3}$. The main factors interfering in the $\mathrm{O}_{3}+\mathrm{PEC}$ process were optimized through UV/vis spectrophotometry, total organic carbon (TOC) and mass spectrometry measurements. After 20 min of treatment using the combined system, 100\% of decolorization was observed while a total mineralization was seen following $60 \mathrm{~min}$ of treatment even in effluents containing $100 \mathrm{ppm}$ AY1. Concomitantly, the combined system $\left(\mathrm{O}_{3}+\mathrm{PEC}\right)$ showed higher decolorization rate constant and lower energy consumption compared to the other techniques, showing that $\mathrm{O}_{3}+\mathrm{PEC}$ is a successful, efficient and cost-effective alternative for water treatment.
\end{abstract}

(c) 2015 Elsevier B.V. All rights reserved.

\section{Introduction}

Photoelectrocatalytic (PEC) treatment of environmental pollutants has been studied over the years [1] and great advances in this area have been reached with the progress in materials research, mainly nanostructured materials and modified/doped semiconductors $[2,3]$. $\mathrm{TiO}_{2}$ is widely employed in photo(electro) catalysis due to its wide range of properties, has the ability to be prepared in various morphologies and energy position of the valence band capable of producing hydroxyl radicals. $\mathrm{TiO}_{2}$ nanotubes $\left(\mathrm{TiO}_{2} \mathrm{NTs}\right)$ have been the subject of many papers in various fields such as solar cells [4], water splitting [5,6], sensors [7], $\mathrm{CO}_{2}$ reduction [8] and as a photocatalyst for the degradation of environmental contaminants $[9,10]$. For photo(electro)catalytic applications, the morphology of the nanotubes has been shown to be the most efficient mainly because of its large surface area and its excellent electronic

\footnotetext{
* Corresponding author. Fax: +55 16 3322-2308.

E-mail address: boldrinv@iq.unesp.br (M.V.B. Zanoni).
}

transport of photogenerated charge carriers, reducing the recombination of electron/hole pair [11].

PEC treatment is embedded on the generation of hydroxyl radicals $(\bullet \mathrm{OH})$, which makes it therefore an intrinsic example of the techniques classified as advanced oxidation processes (AOPs) $[3,12]$. The core of this technique lies in the irradiation of a semiconductor (SC) biased by a potential gradient relatively higher than its flat band potential. The increase in band bending within the $\mathrm{TiO}_{2}$ particles promoted electrons depletion and the enrichment of holes on the SC surface. The photogenerated electrons on the anode are then redirected to the cathode through the electrochemical system, where reduction reactions may occur $[1,3,12,13]$. Thus, the quantum efficiency is increased whilst charges recombination is minimized. However, the main drawback of photoelectrocatalysis lies in its low mineralization efficiency in highly concentrated and colored solutions such as dyes containing wastewater [13]. Under these conditions, much of the radiation emitted by the lamp is absorbed by the solution and does not reach the surface of the photoanode, creating few electron/hole pairs and reducing the ability of generating hydroxyl radicals. 
To circumvent this problem, the combination of photoelectrocatalysis with other advanced oxidation processes is found to lead to high treatment efficiency, besides that, it can be said to be an alternative for the enhancement of the production of hydroxyl radicals $(\bullet \mathrm{OH})$ as well as for the attainment of mineralization of the contaminant in less time and with a higher efficiency [14]. Ozonation is a particularly interesting technique because it is not directly dependent on irradiation, and as a result of the ozone ability to attack double bonds selectively, it can contribute toward the decolorization of the reaction medium, while acting synergistically with photo(electro) catalysis [14,15].

Ozone is a powerful oxidant $(2.07 \mathrm{~V}$ versus $2.8 \mathrm{~V}$ for $\bullet \mathrm{OH})$ that is used in water and wastewater treatment. Ozone can react with organic pollutants via two routes: direct molecular ozone oxidation reaction, which is selective and relatively slow; and/or indirect pathway where $\cdot \mathrm{OH}$ radicals are produced by ozone decomposition, known to be the fastest and non-selective oxidative way (called catalytic ozonation), which is also an AOP. Ozone decomposition is dependent on $\mathrm{pH}$, catalysts and UV irradiation and usually promotes the formation of more recalcitrant compounds in the end of the treatment $[14,16]$.

The literature shows various works with the combination of heterogeneous photocatalysis with ozonation $\left(\mathrm{O}_{3}+\mathrm{PC}\right)[14,15,17,18]$. It is a consensus that ozonation followed by photocatalysis is not as efficient as the two techniques operating simultaneously. However, to our best knowledge, there is no work dealing with simultaneous combination of ozonation with photoelectrocatalysis $\left(\mathrm{O}_{3}+\mathrm{PEC}\right)$. In this context, the present study describes a new annular bubble photoelectrocatalytic reactor combining ozonation and, photoelectrocatalytic oxidation on $\mathrm{TiO}_{2}$ NTs photoanode operating under a bias potential with UV irradiation. Acid Yellow 1 dye was used as a model compound of colorful solution, while the efficiency of the proposed method $\left(\mathrm{O}_{3}+\mathrm{PEC}\right)$ was compared with other systems efficiency $\left(\mathrm{O}_{3}, \mathrm{O}_{3}+\mathrm{UV}, \mathrm{O} 3+\mathrm{PC}, \mathrm{PEC}, \mathrm{PC}\right.$ and UV) and with the optimization of some parameters such as $\mathrm{pH}$, voltage, flow of ozone, dye concentration and irradiation source.

\section{Experimental}

\section{1. $\mathrm{TiO}_{2}$ nanotube arrays electrode preparation}

Photoelectrocatalytic (PEC) experiments were performed using a cylindrical $\mathrm{TiO}_{2}$ nanotube arrays electrode $\left(\mathrm{TiO}_{2} \mathrm{NT}\right)$, with $600 \mathrm{~cm}^{2}$, with a lateral opening for solution flow. The $\mathrm{TiO}_{2} \mathrm{NT}$ was prepared according to the methodology already published previously [10]. Ti sheet was polished using silicon carbide sandpaper of successively finer roughness and cleaned with acetone, isopropanol and finally ultrapure water. The titanium foil was shaped for cylindrical form and $\mathrm{TiO}_{2}$ nanotubes were grown by electrochemical anodization ( $30 \mathrm{~V}$ for $50 \mathrm{~h}$ ) using Minipa MPL-1303 power supply) in an organic electrolyte comprised of $0.25 \%$ ammonium fluoride (98\%, Synth) in glycerol (99.5\%, Synth) containing $10 \%$ volume Milli-Q water. The $\mathrm{TiO}_{2} \mathrm{NT}$ electrode was cleaned in pure water, dried in $\mathrm{N}_{2}$ and annealed at $450{ }^{\circ} \mathrm{C}$ for $30 \mathrm{~min}$ using heating rates of $2{ }^{\circ} \mathrm{Cmin}^{-1}$. The prepared $\mathrm{TiO}_{2} \mathrm{NT}$ was characterized by X-ray diffraction (XRD) on a SIEMENS D5000, DIFFRAC PLUS $\mathrm{XRD}$ Commander $\mathrm{X}$-ray diffractometer with $\mathrm{Cu}-\mathrm{K} \alpha$ radiation. The morphological characterization was carried out by field emission gun-scanning electron microscopy (FEG-SEM) on a JEOL 7500F Microscope.

\subsection{Annular bubble reactor}

The experiments were performed in an annular bubble reactor (ABR) with $63.5 \mathrm{~mm}$ diameter, $1 \mathrm{~L}$ of capacity and sintered glass bubblers at the bottom for injecting $\mathrm{O}_{2} / \mathrm{O}_{3}$. A Pyrex glass tube was positioned at the center of ABR where a UV-B narrowband $36 \mathrm{~W}$ lamp (Philips) or UV-C $36 \mathrm{~W}$ lamp (Osram) was positioned. For PEC experiments, the $\mathrm{TiO}_{2} \mathrm{NT}$ electrode was placed around the glass tube and a graphite rod (diameter of $1.0 \mathrm{~cm}$ ) was used as cathode. The bias voltage was controlled using Minipa PL-1303 power supply.

Ozone was produced by an $03 \mathrm{R}^{\circledR}$ Ozonator model ID-05 (Santa Catarina, Brazil) with a maximum capacity of $5 \mathrm{~g} \mathrm{O}_{3} /$ h. The amount of ozone generated was determined by using an ozone analyzer ANSEROS GM-OEM in $254 \mathrm{~nm}$. The input $\mathrm{O}_{2}$ flow rate was monitored with a Cole-Parmer flowmeter (0.4-5.0 LPM). In the experiments performed without $\mathrm{O}_{3}$ production, $\mathrm{O}_{2}$ was bubbled in the same flow to provide the mass transport. All the experiments were performed in an isolated laboratory and inside a fume cupboard with excellent exhaustion.

\subsection{Acid Yellow 1 degradation}

The Acid Yellow 1 dye (AY1) degradation was carried out using initial concentration of $100 \mathrm{mg} \mathrm{L}^{-1}$ in $\mathrm{Na}_{2} \mathrm{SO}_{4} 0.01 \mathrm{~mol} \mathrm{~L}^{-1}$ with $\mathrm{pH}$ 6.5. The dye was directly dissolved in deionized water. Acid Yellow 1 degradation was monitored removing aliquots at controlled times, which were analyzed by UV/vis spectrophotometry (Hewlett-Packard 8453 spectrophotometer), total organic carbon analyzer (TOC-V $\mathrm{V}_{\mathrm{CPN}}$, Shimadzu) and mass spectrometry.

Different degradations were compared: photoelectrocatalytic oxidation (PEC), photocatalytic oxidation (PC), direct photolysis (UV), ozonation $\left(\mathrm{O}_{3}\right)$, ozonation + UV irradiation $\left(\mathrm{O}_{3}+\mathrm{UV}\right)$, ozonation + photocatalysis $\left(\mathrm{O}_{3}+\mathrm{PC}\right)$ and ozonation + photoelectrocatalysis $\left(\mathrm{O}_{3}+\mathrm{PEC}\right)$.

\section{Results and discussion}

\subsection{Characteristics of $\mathrm{TiO}_{2} \mathrm{NT}$ electrode}

The $\mathrm{TiO}_{2} \mathrm{NT}$ sample prepared by electrochemical anodization was characterized by X-ray diffraction (XRD) in order to confirm the $\mathrm{TiO}_{2}$ phase formed after annealing. Fig. 1 A shows the X-ray diffractogram where the peaks are indexed to the anatase phase formed after annealing the $\mathrm{TiO}_{2} \mathrm{NT}$. It is noteworthy that the formation of anatase phase is desirable once it exhibits a higher charge carrier mobility compared to the rutile [11], thereby contributing toward the minimization of the charges recombination. The morphological characterization was carried out by FEG-SEM and Fig. 1B shows the formation of self-aligned and self-organized nanotubes perpendicularly to the metallic substrate. The $\mathrm{TiO}_{2}$ nanotubes presented an average diameter of $100 \mathrm{~nm}$ and tube wall of $11 \mathrm{~nm}$.

\subsection{Degradation of Acid Yellow 1 hair dye}

Fig. 2A shows a representative spectrum obtained for $100 \mathrm{ppm}$ of AY1 in $0.01 \mathrm{~mol} \mathrm{~L}^{-1} \mathrm{Na}_{2} \mathrm{SO}_{4}$ at $\mathrm{pH} 6.5$ before (Curve a) and after (Curves $b-i$ ) photoelectrocatalytic oxidation conducted with the applied voltage of $+2.0 \mathrm{~V}$ on $\mathrm{TiO}_{2} \mathrm{NT}$ anode and graphite cathodes, using irradiation from a UV-B lamp of $36 \mathrm{~W}$ concomitant to an ozone flow of $1.25 \times 10^{-4} \mathrm{~mol} \mathrm{~min}^{-1}$.

A gradual reduction of absorbance is observed for all the peaks at $205 \mathrm{~nm}$ and $257 \mathrm{~nm}$ in the UV region which were attributed to the aromatics groups while 393 and $430 \mathrm{~nm}$ were attributed to the chromophore groups. Graphs of Fig. 2B illustrate the decolorization observed at $430 \mathrm{~nm}$. As compared in Fig. 2B, the color removal is $100 \%$ after 30 min of $\mathrm{O}_{3}+$ PEC treatment. Nevertheless, a similar behavior was obtained for the ozonation process (Fig. 2B), indicating that the fast oxidation in both processes promotes similar decolorization. However, when the TOC removal is compared 

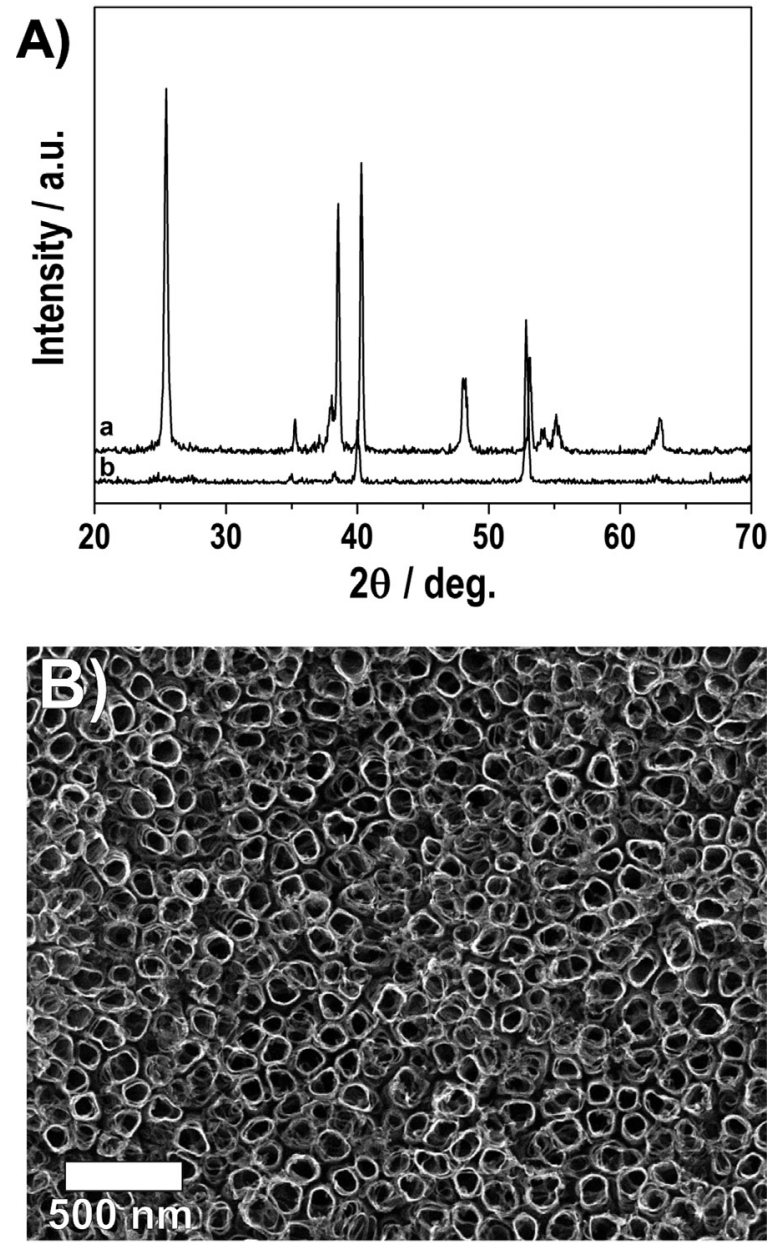

Fig. 1. (A) X-ray diffractrogram of (a) annealed $\mathrm{TiO}_{2} \mathrm{NTs}$ sample and (b) prior to annealing $\mathrm{TiO}_{2}$ sample and (B) FEG-SEM top view image of $\mathrm{TiO}_{2}$ nanotubes electrode

(Fig. 2B), it is clear that the mineralization is found to be around 4 times higher compared to the $\mathrm{O}_{3}+$ PEC system following $60 \mathrm{~min}$ of treatment. This shows that the combination of these two techniques is an efficient way to increase the degradation rate of Acid Yellow 1, due to the enhanced $\cdot \mathrm{OH}$ generation formed by photoelectrocatalysis and photocatalytic decomposition of ozone [14].

In order to improve the degradation efficiency using the proposed method $\left(\mathrm{O}_{3}+\mathrm{PEC}\right)$, the degradation of AY1 was investigated testing the effect of the $\mathrm{pH}$ range (3, 6.5 and 9); applied voltage $(0.5 \mathrm{~V}, 2.0 \mathrm{~V}$ and $4.0 \mathrm{~V})$ and UV lamp emitting in UV-B and UV-C region.

\subsubsection{Effect of $p H$}

The influence of $\mathrm{pH}\left(3,6.5\right.$ and 9) in the oxidation of $100 \mathrm{mg} \mathrm{L}^{-1}$ AY1 dye in $\mathrm{Na}_{2} \mathrm{SO}_{4} 0.01 \mathrm{M}$ was determined by using a $\mathrm{O}_{3}$ flow of $1.25 \times 10^{-4} \mathrm{~mol} \mathrm{~min}^{-1}$ and the $\mathrm{TiO}_{2} \mathrm{NTs}$ operating at $2.0 \mathrm{~V}$ under UV-B $36 \mathrm{~W}$ irradiation. After $90 \mathrm{~min}$ of treatment, the decolorization is found to be $100 \%$ in all the investigated pH when AY1 is treated by $\mathrm{O}_{3}$ or $\mathrm{O}_{3}+$ PEC. The total decolorization time was $30 \mathrm{~min}$ for all the studied pHs using the ozonation treatment. In $\mathrm{O}_{3}+\mathrm{PEC}$ system, at $\mathrm{pH} 3$, total decolorization is reached following $20 \mathrm{~min}$ of treatment and $30 \mathrm{~min}$ is required at $\mathrm{pH} 6.5$ and 9 (data not shown). Nevertheless, the total organic carbon (TOC) removal for the ozonation process (Fig. 3A) and ozonation combined with photoelectrocatalysis $\left(\mathrm{O}_{3}+\mathrm{PEC}\right)$ are very different as shown in Fig. 3 .

Using pure ozonation (Fig. 3A) pH 6.5 and 9 promoted a slightly better performance in TOC removal compared to $\mathrm{pH}$ 3. This can be explained because the catalytic ozonation process (ozone con-
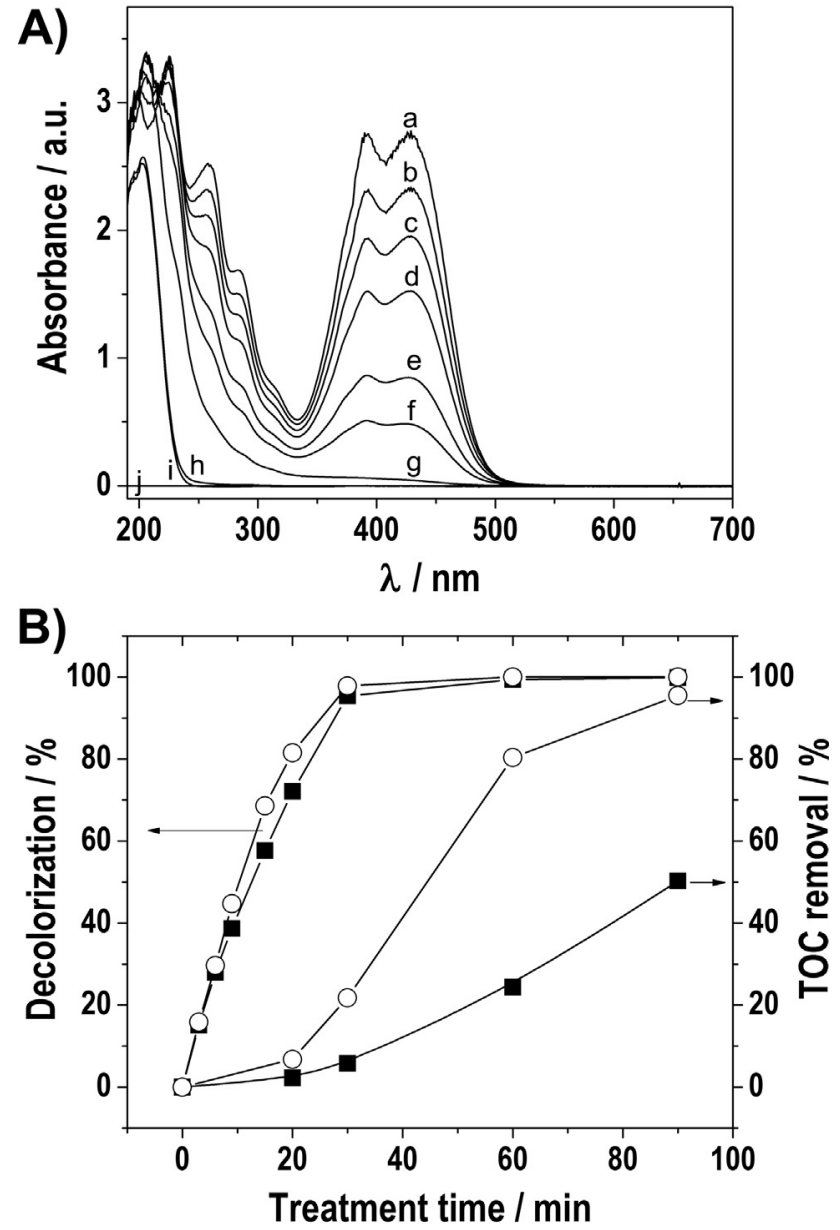

Fig. 2. (A) Representative spectrum of $100 \mathrm{ppm}$ AY1 dye during $\mathrm{O}_{3}+\mathrm{PEC}$ treatment for (a) $0 \mathrm{~min}$; (b) $3 \mathrm{~min}$; (c) $6 \mathrm{~min}$; (d) $9 \mathrm{~min}$; (e) $15 \mathrm{~min}$; (f) $20 \mathrm{~min}$; (g) $30 \mathrm{~min}$; (h) $60 \mathrm{~min}$; (i) $90 \mathrm{~min}$ and (j) blank; and (B) Decolorization (\%) and TOC removal (\%) of 100 ppm AY1 dye during $(\bigcirc) \mathrm{O}_{3}+\mathrm{PEC}$ and $(\boldsymbol{\square}) \mathrm{O}_{3}$ treatment. Conditions: $100 \mathrm{mg} \mathrm{L}^{-1}$ AY1 dye in $0.01 \mathrm{M} \mathrm{Na}_{2} \mathrm{SO}_{4}, \mathrm{pH} 6.5, \mathrm{O}_{3}$ flow of $1.25 \times 10^{-4} \mathrm{~mol} \mathrm{~min}^{-1} ; V_{\text {app }}=2.0 \mathrm{~V}$, UV-B $36 \mathrm{~W}$ lamp.

version to hydroxyl radicals) is dependent on a slightly alkaline medium (Eq. (1)), which can attack the organic molecules via indirect oxidation process, as shown in Eq. (2) (where Rox represents an oxidized product) $[14,15]$. At an acidic $\mathrm{pH}$, the ozone directly attacks the molecules (called ozonolysis) especially $\mathrm{C}=\mathrm{C}$ double bonds resulting in the formation of carboxylic acids which can be recalcitrant in relation to the ozone action [14] (Eq. (3)).

$\mathrm{O}_{3}+\mathrm{OH}^{-} \rightarrow \cdot \mathrm{OH}+\left(\mathrm{O}_{2}^{\bullet} \leftrightarrow \mathrm{HO}_{2}^{\bullet}\right)$

$\bullet \mathrm{OH}+\mathrm{R}^{\bullet} \rightarrow$ Rox

$\mathrm{O}_{3}+\mathrm{R} \rightarrow \operatorname{Rox}$

When the $\mathrm{O}_{3}+$ PEC system are tested, the maximum efficiency occurs at an acidic $\mathrm{pH}$. This is also the optimum condition for PEC oxidation, where the target dye is adsorbed on the electrode surface via electrostatic interaction. Considering that the zero charge of $\mathrm{TiO}_{2}$ presents $\mathrm{pH}_{\mathrm{pzc}}$ around 5.3 and the $\mathrm{p} K_{\mathrm{a}}$ for sulphonated dyes occurs around 2.0, maximum adsorption could be occurring in acid medium when $\mathrm{TiO}_{2}$ is positively charged $[9,19]$.

Moreover, under the combined process of $\mathrm{O}_{3}+\mathrm{PEC}$, there is the photocatalytic decomposition of ozone (to form hydroxyl radicals) (Eqs. (4-7)). The photogenerated electron on $\mathrm{TiO}_{2}$ conduction band (CB) (Eq. (4)) can also react with the ozone generating ozonide radicals $\left(\mathrm{O}_{3}{ }^{-}\right)$(Eq. (5)). The photocatalytic decomposition of ozone is dependent on the $\mathrm{pH}$, because ozonide radicals react with $\mathrm{H}^{+}$in the 

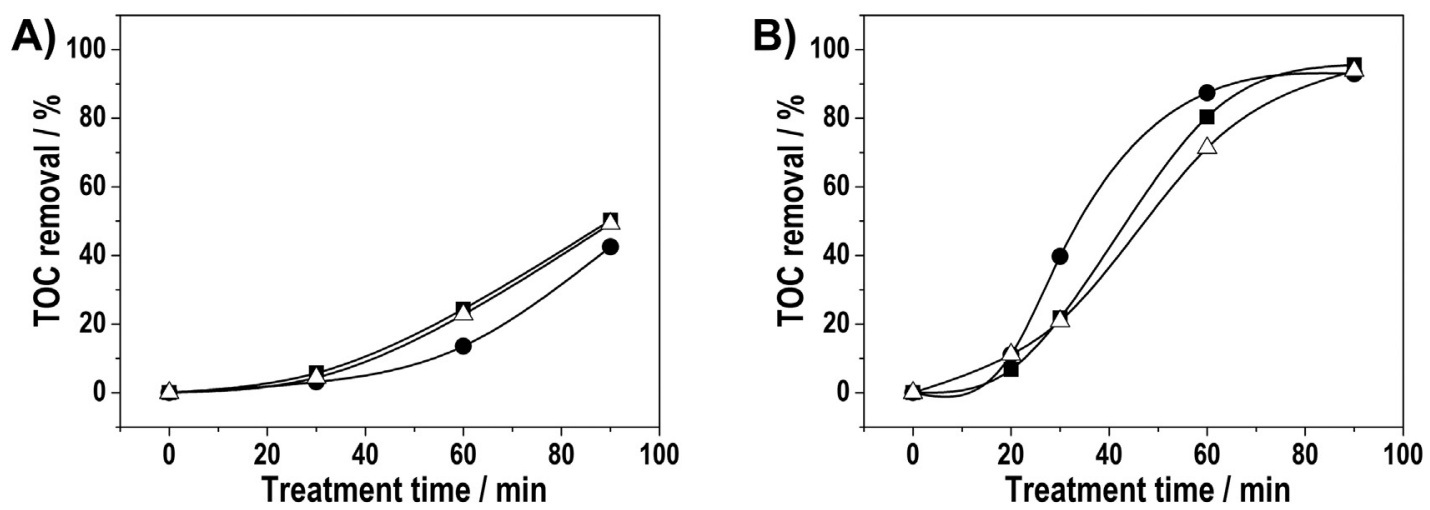

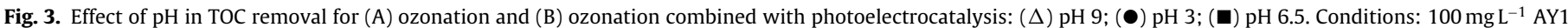
dye in $\mathrm{Na}_{2} \mathrm{SO}_{4} 0.01 \mathrm{M}, \mathrm{O}_{3}$ flow of $1.25 \times 10^{-4} \mathrm{~mol} \mathrm{~min}^{-1}, V_{\text {app }}=2.0 \mathrm{~V}$, UV-B $36 \mathrm{~W}$ lamp.

solution to produce $\mathrm{HO}_{3}{ }^{\bullet}$ radicals (Eq. (6)), which decomposes in $\mathrm{OH}^{\bullet}$ (Eq. (7)) [14,15]:

$\mathrm{TiO}_{2}+h v \rightarrow \mathrm{TiO}_{2}-\mathrm{e}^{-}+\mathrm{TiO}_{2}-\mathrm{h}^{+}$

$\mathrm{O}_{3}+\mathrm{TiO}_{2}-\mathrm{e}^{-} \rightarrow \mathrm{O}_{3}{ }^{-}$

$\mathrm{O}_{3}{ }^{-}+\mathrm{H}^{+} \rightarrow \mathrm{HO}_{3} \cdot$

$\mathrm{HO}_{3}^{\bullet} \rightarrow \mathrm{O}_{2}+\mathrm{OH}^{\bullet}$

In addition, the hydroxyl radical can be produced by ultraviolet irradiation of dissolved ozone according to the following reactions [14,20]:

$\mathrm{O}_{3}+\mathrm{H}_{2} \mathrm{O}+h v \rightarrow \mathrm{H}_{2} \mathrm{O}_{2}+\mathrm{O}_{2}$

$\mathrm{H}_{2} \mathrm{O}_{2}+h v \rightarrow 2 \mathrm{OH}^{\bullet}$

$\mathrm{H}_{2} \mathrm{O}_{2} \leftrightarrow \mathrm{HO}_{2}^{-}+\mathrm{H}^{+}$

$\mathrm{O}_{3}+\mathrm{HO}_{2}^{-} \rightarrow \mathrm{O}_{3}^{\cdot-}+\mathrm{HO}_{2} \cdot$

$\mathrm{HO}_{2}{ }^{\bullet} \rightarrow \mathrm{O}_{2}{ }^{-}+\mathrm{H}^{+}$

$\mathrm{O}_{3}+\mathrm{O}_{2}{ }^{-} \rightarrow \mathrm{O}_{3}{ }^{-}+\mathrm{O}_{2}$

$\mathrm{O}_{3}{ }^{-}+\mathrm{H}^{+} \leftrightarrow \mathrm{HO}_{3} \cdot$

According to the above mechanism, ozonide radicals are generated (Eq. (13)), which under acidic conditions can produce hydroxyl radicals (Eqs. (6) and (7)) responsible for the mineralization of the AY1 dye.

Thus, the acidic medium increases the AY1 dye degradation rate in the $\mathrm{O}_{3}+\mathrm{PEC}$ process. Another important feature of this system has to do with the ozone contribution in overcoming the underlying demerit of photoelectrocatalysis operating in high concentrated solutions which tend to decrease the amount of light reaching the photoanode. The direct ozone attack decreases the color of the reaction medium with the formation of colorless intermediates, collaborating toward the synergistic reaction between the two processes.

\subsubsection{Effect of applied voltage}

In a photoelectrocatalytic process, the applied voltage is directly related to the band bending and the improvement of the charges separation [3,21]. Fig. 4 shows the effect of applied voltage in the performance of TOC removal during $\mathrm{O}_{3}+\mathrm{PEC}$ treatment. There is no significant improvement in mineralization when the different applied voltages are evaluated. This behavior is observed owing to the fact that all the applied voltages were found to be greater than the flat band potential of $\mathrm{TiO}_{2}\left(E_{\mathrm{fb}}\right.$ around $\left.-0.15 \mathrm{~V}\right)$, indeed greater enough to cause a complete band bending, promoting a more efficient separation of the photogenerated electrons and holes

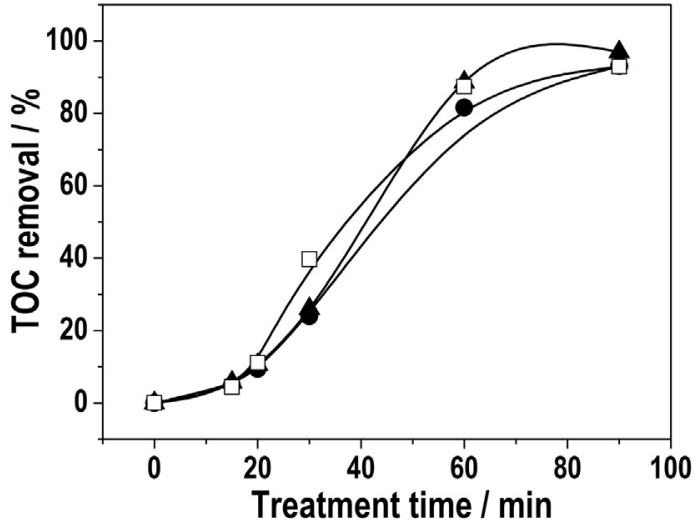

Fig. 4. Effect of applied potential in the TOC removal (\%) during $\mathrm{O}_{3}+\mathrm{PEC}$ treatment: (๑) $0.5 \mathrm{~V}$; $\square$ ) $2.0 \mathrm{~V}$; ( $\Delta$ ) $4.0 \mathrm{~V}$. Conditions: $100 \mathrm{mg} \mathrm{L}^{-1} \mathrm{AY} 1$ dye in $0.01 \mathrm{M} \mathrm{Na}_{2} \mathrm{SO}_{4}, \mathrm{pH}$ $3, \mathrm{O}_{3}$ flow of $1.25 \times 10^{-4} \mathrm{~mol} \mathrm{~min}^{-1}$, UV-B $36 \mathrm{~W}$ lamp.

[3]. Remarkably though, a high bias potential was avoided aiming at minimizing the oxygen evolution during the photoelectrocatalytic process and a voltage of $+2.0 \mathrm{~V}$ was chosen in further experiments.

\subsubsection{Effect of lamp emission}

The influence of UV irradiation on the $\mathrm{O}_{3}+\mathrm{PEC}$ treatment was evaluated using two sources: (i) a UV-B $36 \mathrm{~W}$ lamp with emission between 305 and $315 \mathrm{~nm}$ with a peak of $311 \mathrm{~nm}$; and ii) UV-C $36 \mathrm{~W}$ lamp with emission peak of $254 \mathrm{~nm}$. Fig. 5 shows the influence of these UV lamps in TOC removal (\%) of $100 \mathrm{mg} \mathrm{L}^{-1} \mathrm{AY} 1$ dye in $\mathrm{Na}_{2} \mathrm{SO}_{4}$ $0.01 \mathrm{M} \mathrm{pH} 3$ treated for $90 \mathrm{~min}\left(\mathrm{O}_{3}\right.$ flow of $1.25 \times 10^{-4} \mathrm{~mol} \mathrm{~min}^{-1}$ and the $\mathrm{TiO}_{2} \mathrm{NTs}$ and bias potential of $2.0 \mathrm{~V}$ ). It is worth pointing out the clear diminishing that can be seen in the degradation efficiency of the $\mathrm{O}_{3}+$ PEC system when the photoanode is irradiated by UV-C lamp. This outcome can be said to be due to the absorption of wavelengths shorter than $300 \mathrm{~nm}$ by the borosilicate glass, as can be seen in Fig. 5B. Thus, smaller quantities of photons from UV-C lamp are able to reach the $\mathrm{TiO}_{2}$ NTs electrode, consequently decreasing the formation of hydroxyl radicals. These results indicate that hydroxyl radicals formation still plays an essentially important role in the system.

\subsubsection{Effect of $\mathrm{O}_{3}$ concentration}

Clearly enough, it is expected that the increasing ozone flow results in fast degradation. The performance of TOC removal was evaluated testing three different flows of ozone $1.25 \times 10^{-4}$, $3.85 \times 10^{-4}$ and $6.35 \times 10^{-4} \mathrm{~mol} \mathrm{O}_{3} \mathrm{~min}^{-1}$ (equivalent to $0.36,1.11$ and $1.83 \mathrm{~g} \mathrm{O}_{3} / \mathrm{h}$, respectively). The decolorization was found to reach $100 \%$ in all the investigated system (data not shown). Fig. 6 
A)
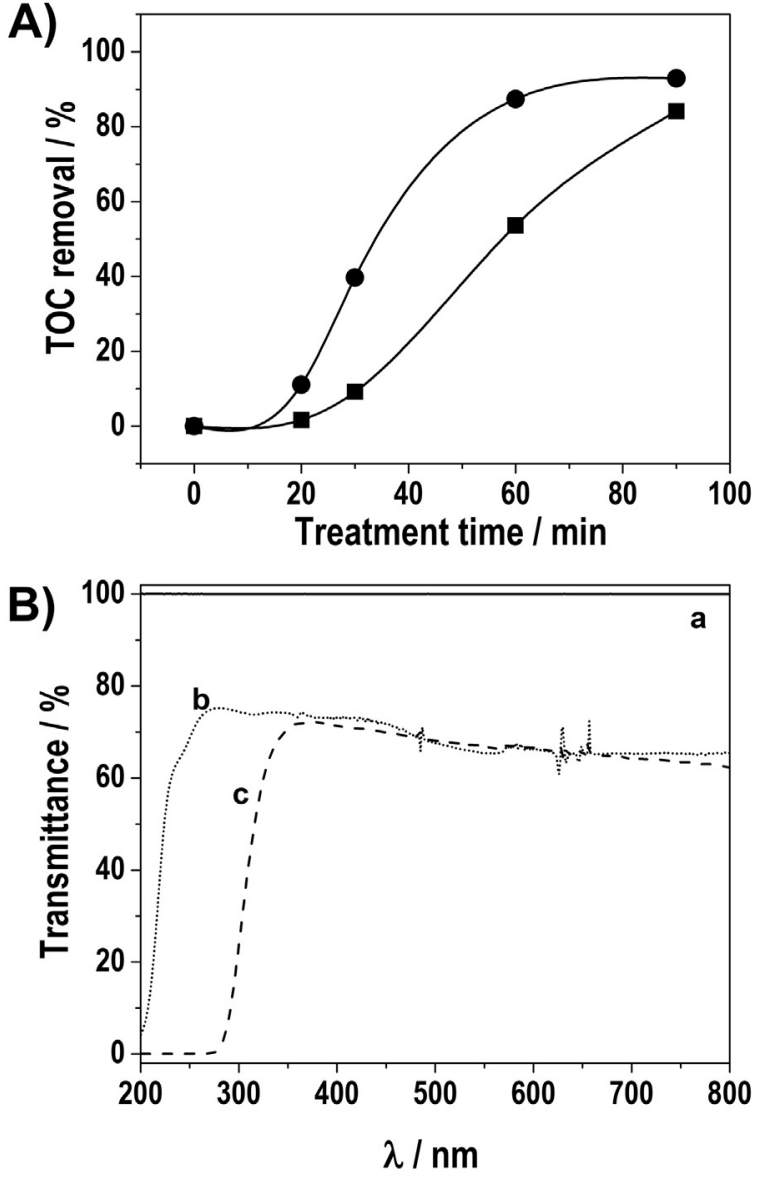

Fig. 5. (A) Effect of UV lamps on the mineralization efficiency for $\mathrm{O}_{3}+\mathrm{PEC}$ treatment: (๑)UV-B lamp and (ם)UV-C lamp. Conditions: $100 \mathrm{mg} \mathrm{L}^{-1}$ AY1 dye in $0.01 \mathrm{M} \mathrm{Na}_{2} \mathrm{SO}_{4}$, $\mathrm{pH} 3, \mathrm{O}_{3}$ flow of $1.25 \times 10^{-4} \mathrm{~mol} \mathrm{~min}^{-1}, V_{\mathrm{app}}=2.0 \mathrm{~V}$. (B) Transmittance (\%) of: (a) air; (b) quartz and (c) borosilicate glass used in the experiments.

shows the influence of $\mathrm{O}_{3}$ flow in $\mathrm{O}_{3}+$ PEC treatment (Fig. 6A) and in pure ozonation (Fig. $6 \mathrm{~B}$ ). The results illustrate that the combined process clearly exerts a critically decisive role when it comes to the improvement of the dye mineralization.

During the $\mathrm{O}_{3}+$ PEC treatment (Fig. 6A), one can notice that increasing the ozone flow results in higher mineralization rates, reaching almost complete mineralization following 30 min of treatment. This is undoubtedly a reflex of the increased amount of hydroxyl radicals being formed by the photocatalytic decomposition of ozone. In addition, the faster decolorization of the dye

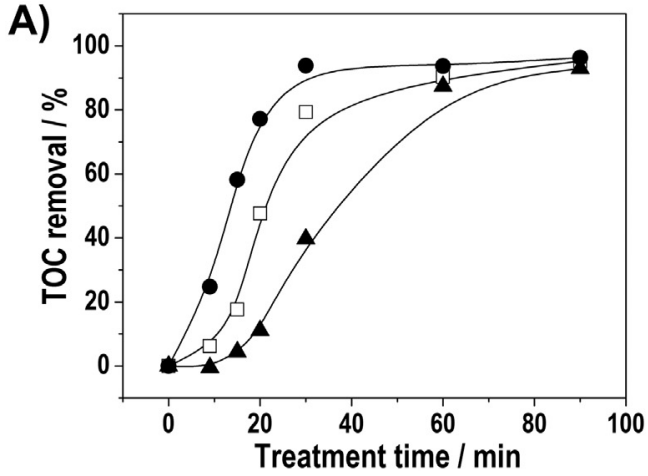

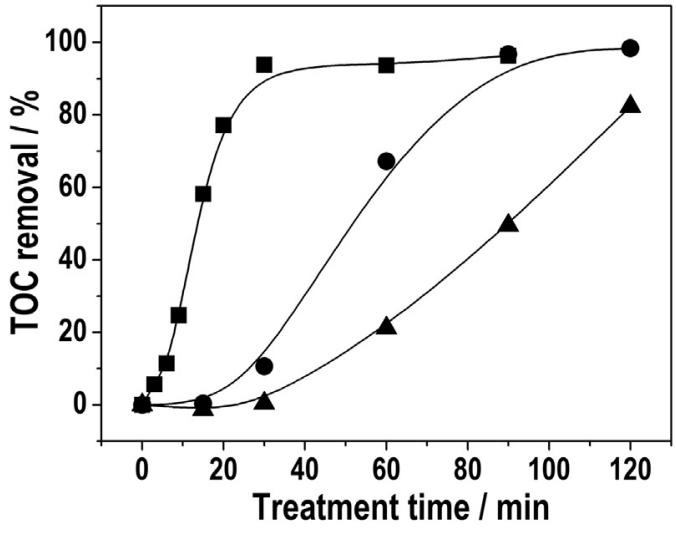

Fig. 7. Effect of initial concentration of AY1 on the mineralization efficiency for

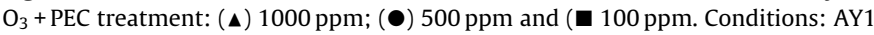
dye in $0.01 \mathrm{M} \mathrm{Na}_{2} \mathrm{SO}_{4}, \mathrm{pH} 3, \mathrm{O}_{3}$ flow of $6.35 \times 10^{-4} \mathrm{~mol} \mathrm{~min}^{-1}, V_{\text {app }}=2.0 \mathrm{~V}$, UV-B lamp.

is seen to lead to an improvement in the light absorption of the photoanode.

The degradation rate is decreased in pure ozonation, as shown in Fig. 6B. The increased flow of ozone accelerates the rate of TOC removal, but the maximum mineralization is limited to $\approx 50 \%$. As aforementioned, the mechanism of degradation using only the $\mathrm{O}_{3}$ system occurs through the direct reaction of ozone whose predominance of reaction is by a selective attack resulting in non-reactive products of degradation.

\subsubsection{Effect of Acid Yellow 1 initial concentration}

Fig. 7 shows the effect of the dye concentration $(100,500$ and $1000 \mathrm{ppm}$ ) in $0.01 \mathrm{M} \mathrm{Na} \mathrm{SO}_{4}, \mathrm{pH} 3$ using $\mathrm{O}_{3}$ flow of $6.35 \times 10^{-4} \mathrm{~mol} \mathrm{~min}^{-1}$, applied potential of $2.0 \mathrm{~V}$ and UV-B lamp in the $\mathrm{O}_{3}+\mathrm{PEC}$ oxidation. An increase in the concentration from $100 \mathrm{ppm}$ to $500 \mathrm{ppm}$ leads to an increase in the degradation time necessary to reach total mineralization from $30 \mathrm{~min}$ to $90 \mathrm{~min}$, and as already expected, increasing the concentration triggers a reduction in the degradation rate. These effects can be explained on grounds of the decrease in the light intensity that reaches the $\mathrm{TiO}_{2}$ surface due to the diminishing transparency of the solution into a more concentrated solution (from 5 up to 10 times more).

The results indicate that even at a concentration so high as $1000 \mathrm{ppm}$ it is possible to achieve complete decolorization and up to $80 \%$ of mineralization within $120 \mathrm{~min}$.

\subsubsection{Effect of ozonation, photoelectrocatalysis, photocatalysis} and combined systems on dye degradation

In order to prove the superior performance of $\mathrm{O}_{3}+\mathrm{PEC}$ system in relation to $\mathrm{O}_{3}$ (ozonation), $\mathrm{O}_{3}+\mathrm{UV}$ (ozonation and UV

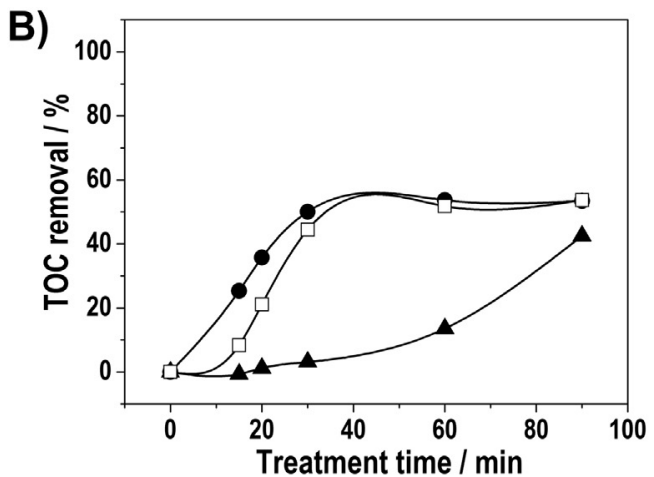

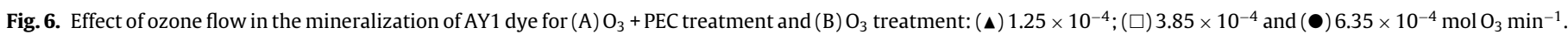
Conditions: $100 \mathrm{mg} \mathrm{L}^{-1} \mathrm{AY} 1$ dye in $\mathrm{Na}_{2} \mathrm{SO}_{4} 0.01 \mathrm{M}, \mathrm{pH} 3$, UV-B $36 \mathrm{~W}$ lamp and $V_{\text {app }}=2.0 \mathrm{~V}$. 

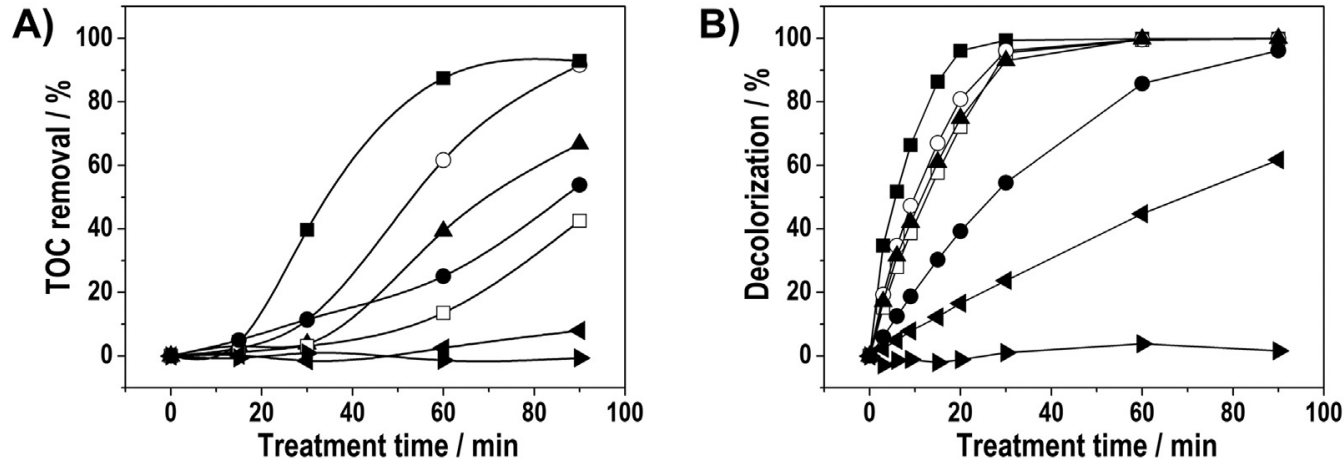

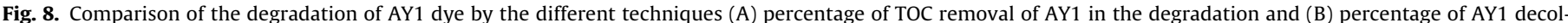

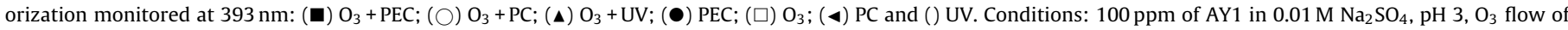
$1.25 \times 10^{-4} \mathrm{~mol} \mathrm{~min}^{-1}$, UV-B $36 \mathrm{~W}$ lamp and $V_{\mathrm{app}}=2.0 \mathrm{~V}$.

Table 1

Decolorization rate constant $(k)$ obtained for $\ln \left[A / A_{0}\right]$ versus time plot during degradation of $100 \mathrm{mg} \mathrm{L}^{-1} \mathrm{AY} 1$ dye in $0.01 \mathrm{~mol} \mathrm{~L}^{-1} \mathrm{Na}_{2} \mathrm{SO}_{4}$ at $\mathrm{pH} 3$; UV-B $36 \mathrm{~W}$ lamp and $V_{\text {app }}=+2.0 \mathrm{~V}$ under different systems.

\begin{tabular}{lll}
\hline Treatment system & $\mathrm{k} /\left(\mathrm{min}^{-1}\right)$ & $R^{2}$ \\
\hline $\mathrm{PC}$ & -0.0090 & 0.9989 \\
$\mathrm{PEC}$ & -0.0250 & 0.9983 \\
$\mathrm{O}_{3}$ & -0.0627 & 0.9924 \\
$\mathrm{O}_{3}+\mathrm{UV}$ & -0.0676 & 0.9947 \\
$\mathrm{O}_{3}+\mathrm{PC}$ & -0.0811 & 0.9924 \\
$\mathrm{O}_{3}+\mathrm{PEC}$ & -0.1558 & 0.9751 \\
\hline
\end{tabular}

irradiation), $\mathrm{O}_{3}+\mathrm{PC}$ (ozonation and photocatalysis using $\mathrm{TiO}_{2} \mathrm{NT}$ without applied voltage), $\mathrm{PEC}$ (photoelectrocatalysis using $\mathrm{TiO}_{2} \mathrm{NT}$ ), PC (photocatalysis using $\mathrm{TiO}_{2} \mathrm{NT}$ without applied voltage) and UV (direct photolysis with UV irradiation) the decolorization and mineralization of $100 \mathrm{ppm}$ of AY1 were monitored during $90 \mathrm{~min}$ in $0.01 \mathrm{M} \mathrm{Na}_{2} \mathrm{SO}_{4}, \mathrm{pH} 3$, using $\mathrm{O}_{3}$ flow of $1.25 \times 10^{-4} \mathrm{~mol} \mathrm{~min}^{-1}$, UV-B $36 \mathrm{~W}$ lamp and $V_{\mathrm{app}}=2.0 \mathrm{~V}$ for the studied systems. The results are shown in Fig. 8.

The results indicate that the combination of photoelectrocatalysis and ozonation is much more efficient compared to the $\mathrm{O}_{3}+\mathrm{PC}$ as the former leads to a relatively much faster decolorization and mineralization. Some works have proven that the combination of $\mathrm{O}_{3}+\mathrm{PC}$ results in a synergistic effect and have shown such a combination to be an efficient way of degrading organic pollutants $[14,15,22-24]$. Nevertheless, by a simple application of a voltage using a power supply it is possible to reach mineralization of about $90 \%$ in 60 min of treatment, while in $\mathrm{O}_{3}+\mathrm{PC}$ the TOC removal is $60 \%$ at the same time (a gain of about 1.4 times). Moreover, $\mathrm{O}_{3}+\mathrm{PEC}$ provides not only a sum of isolated $\mathrm{O}_{3}$ and PEC processes, but it is a synergistic process.

It can also be observed that treatments based on ozonation $\left(\mathrm{O}_{3}\right.$, $\mathrm{O}_{3}+\mathrm{UV}, \mathrm{O}_{3}+\mathrm{PC}$ e $\mathrm{O}_{3}+\mathrm{PEC}$ ) result in rapid decolorization. However, $\mathrm{O}_{3}$ treatment results in low mineralization, as seen in Fig. 8B. In $\mathrm{O}_{3}+\mathrm{UV}$ treatment, a relatively higher TOC removal (\%) is seen compared to that observed in pure ozonation as a result of the generation of hydroxyl radicals, shown in Eqs. (5-7).

The decolorization kinetics follows a pseudo-first-order reaction (Langmuir-Hinshelwood kinetics) and the obtained constant rates of decolorization under the different systems are presented in Table 1 . As can be observed, the $\mathrm{O}_{3}+$ PEC system has a rate constant almost 2 times higher than the $\mathrm{O}_{3}+\mathrm{PC}$ system, which is in accord with the results shown in Fig. 8 indicating that this novel combination of photoelectrocatalysis and ozonation can considerably improve the results of photocatalytic ozonation which has already been well-established in the literature [14].

\subsection{Energy consumption}

For the purpose of choosing the best method for wastewater treatment, some significant factors ought to be taken under consideration including economics, effluent quality goals, regulations, operation, among others. However, economics is often the most relevant factor considered in this case and as we know AOPs are electric-energy-intensive, hence electric energy can represent the main operating cost $[25,26]$. Bolton et al. [25] have established standard figures-of-merit for the comparison of energy consumption independent of the nature of the system. The electrical energy per $\operatorname{order}\left(E_{\mathrm{EO}}, \mathrm{kWh} / \mathrm{m}^{3} /\right.$ order $)$ is the electric energy in kilowatt hours $[\mathrm{kWh}]$ required to degrade a contaminant by one order of magnitude in a unit volume $\left(1 \mathrm{~m}^{3}\right)$ (Eq. (15)) and it is used when the concentration of contaminant is low where the degradation follows a first-order kinetics.

$E_{\mathrm{EO}}=\frac{P \times t \times 1000}{V \times \log \frac{\left(\mathrm{AY} 1_{\mathrm{i}}\right)}{\left(\mathrm{AY} 1_{\mathrm{f}}\right)}}$

Where $P$ stands for the rated power $(\mathrm{kW})$ of the oxidation system, $t$ being the treatment time $(\mathrm{h}), \mathrm{V}$ the treated volume $(1 \mathrm{~L})$ and $A Y 1_{\mathrm{i}}$ and $A Y 1_{\mathrm{f}}$ the initial and final AY1 dye concentrations after the $t$ treatment time. The rated power is known to be equal to the sum of the individual energy consumption (EC) of the ozonator, the lamp and the power supply. The consumption of each equipment (in Wh) was calculated measuring consumed current and the utility voltage during operation with a multimeter (Minipa ET-2042D). The lamp consumes $36 \mathrm{Wh}$, the power supply consumes $8.7 \mathrm{Wh}$ and the ozonator consumes $54.5,58.9$ and $67.6 \mathrm{Wh}$ when it is producing $1.25 \times 10^{-4}, 3.85 \times 10^{-4}$ and $6.35 \times 10^{-4} \mathrm{~mol} \mathrm{O}_{3} / \mathrm{min}$, respectively.

Taking $9 \mathrm{~min}$ as the treatment time for the calculation of $E_{\mathrm{EO}}$, Table 2 shows the $E_{\mathrm{EO}}$ values for the different system studied. Comparing the different systems, $\mathrm{O}_{3}+$ PEC showed the lowest $E_{\mathrm{EO}}$, for a fixed ozone flow. This indicates that the combination of ozonation and photoelectrocatalysis is the best treatment system both in respect to cost and degradation rate of AY1 dye. These results also indicate that increasing the ozone flow in $\mathrm{O}_{3}+$ PEC from $1.25 \times 10^{-4}$ to $3.85 \times 10^{-4}$ and $6.35 \times 10^{-4} \mathrm{molO}_{3} / \mathrm{min}$, the $E_{\mathrm{EO}}$ is decreased substantially from 31.5 to 10.5 and $6.6 \mathrm{kWh} / \mathrm{m}^{3} /$ order, respectively, indicating best values of efficiency (consumption/removal ratio). The great advantage of the $\mathrm{O}_{3}+\mathrm{PEC}$ relative to the $\mathrm{O}_{3}+\mathrm{PC}$ system lies in the applied potential which dramatically increases the efficiency of degradation (due to better separation of charges in the semiconductor and the improved catalytic conversion of $\mathrm{O}_{3}$ ). As the power supply has a relatively small energy consumption and leads to a large improvement of \% degradation, the $\mathrm{O}_{3}+\mathrm{PEC}$ system is undoubtedly expected to present a lower specific energy consumption as compared to the $\mathrm{O}_{3}+\mathrm{PC}$ and the other systems. 
Table 2

Electrical energy per order for AY1 degradation using different systems. 100 ppm of AY1 in $0.01 \mathrm{M} \mathrm{Na}_{2} \mathrm{SO}_{4}, \mathrm{pH} 3, \mathrm{UV}-\mathrm{B} 36 \mathrm{~W}$ lamp and $V_{\mathrm{app}}=2.0 \mathrm{~V}$.

\begin{tabular}{|c|c|c|c|}
\hline $\begin{array}{l}\text { Treatment } \\
\text { system }\end{array}$ & $\begin{array}{l}\text { Ozone flow } \\
\left(\mathrm{mol} \mathrm{min}^{-1}\right)\end{array}$ & $\begin{array}{l}\text { AY1 degradation } \\
(\%) \text { in } 9 \mathrm{~min}\end{array}$ & $\begin{array}{l}\text { Electrical energy per order } \\
\left(\mathrm{kWh} / \mathrm{m}^{3} / \text { order }\right) \text { in } 9 \mathrm{~min}\end{array}$ \\
\hline PC & - & 7.8 & 152.3 \\
\hline PEC & - & 18.7 & 74.7 \\
\hline $\mathrm{O}_{3}$ & $1.25 \times 10^{-4}$ & 38.7 & 38.5 \\
\hline $\mathrm{O}_{3}+\mathrm{UV}$ & $1.25 \times 10^{-4}$ & 42.1 & 57.2 \\
\hline $\mathrm{O}_{3}+\mathrm{PC}$ & $1.25 \times 10^{-4}$ & 47.2 & 48.9 \\
\hline $\mathrm{O}_{3}+\mathrm{PEC}$ & $1.25 \times 10^{-4}$ & 66.3 & 31.5 \\
\hline $\mathrm{O}_{3}+\mathrm{PEC}$ & $3.85 \times 10^{-4}$ & 96.7 & 10.5 \\
\hline $\mathrm{O}_{3}+\mathrm{PEC}$ & $6.35 \times 10^{-4}$ & 99.4 & 6.6 \\
\hline
\end{tabular}

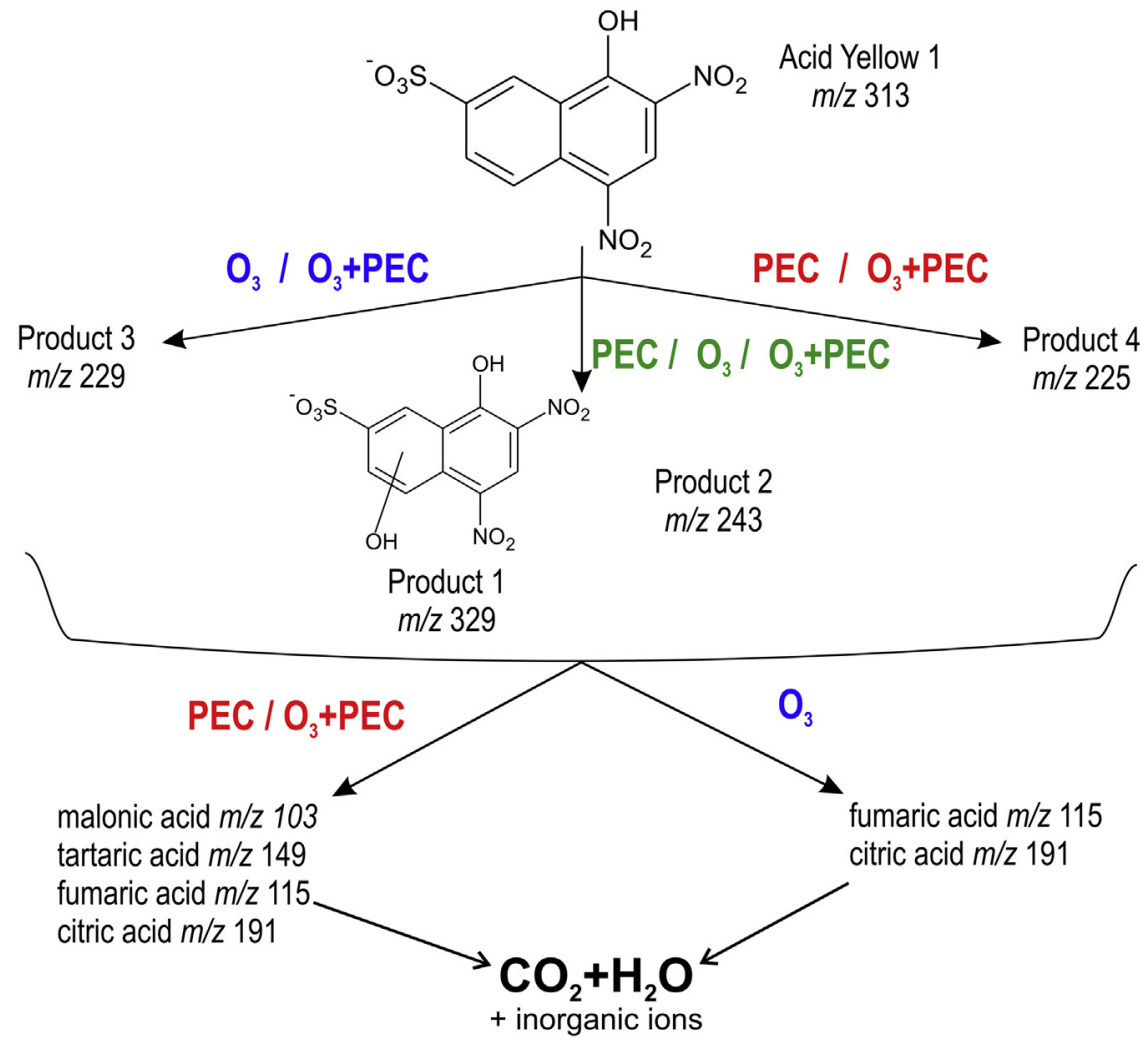

Scheme 1. AY1 dye proposed degradation pathway by different degradation processes.

Nevertheless, this calculation does not consider the system's efficiency in the dye mineralization. Although pure ozonation is said to be efficient in the removal of AY1 dye and has shown to be the second lowest $E_{\mathrm{EO}}$ value, it has not been possible to achieve TOC removal above $50 \%$ in this system.

\subsection{Degradation intermediates of Acid Yellow 1 by LC-MS/MS analysis}

It is known that during the degradation of organic compounds by AOPs various byproducts can be formed. In this context, aromatic and aliphatic intermediates formed during the AY1 degradation solutions were identified by LC-MS/MS.

The identification of the target AY1 dye and its main degradation products revealed by $m / z$ transition detected in the negative mode was obtained by LightSight ${ }^{\circledR}$ software. The software data compared all the samples directly before subtracting them from the control or initial experiment sample. The results showed without any doubts the main difference between the chromatograms and the products formed. After analyzing all the experiments through LightSight ${ }^{\circledR}$, including the optimized MRM and fullscan experiments, four main products were detected. The products detected were: $1(\mathrm{~m} / \mathrm{z} 329)$ and $2(\mathrm{~m} / \mathrm{z} 243)$, which were present in all the three treatments performed $\left(\mathrm{O}_{3}\right.$, PEC and $\left.\mathrm{O}_{3}+\mathrm{PEC}\right)$, probably due to the capacity of hydroxyl radical to be formed during all the treatments used. The product $3(\mathrm{~m} / \mathrm{z} 229)$ was detected in $\mathrm{O}_{3}$ and $\mathrm{O}_{3}+$ PEC treatments, indicating that this product can be formed only during the treatment using $\mathrm{O}_{3}$. The product $4(\mathrm{~m} / \mathrm{z} 225)$ was detected in $\mathrm{O}_{3}+$ PEC and PEC treatments, indicating that the PEC treatment was responsible for this product formation. The product identified as compound 1 was generated by oxidation (MW 330, m/z 329), where oxygen (16 Da) was introduced in the AY1, the position of hydroxylation cannot be completely elucidated only by LC-MS/MS analyses. The following products $\mathbf{2 , 3}$ and $\mathbf{4}$ were not completely elucidated even with the MS/MS experiments performed. New experiments are underway to identify the products obtained.

The presence of aliphatic acids and aromatic acids were also investigated. Optimized MRM experiments were carried out owing to the high sensibility found in the LC-MS/MS analyses. The results showed the presence of malonic, fumaric, tartaric and citric acids in $\mathrm{O}_{3}+$ PEC and PEC treatments. On the other hand, fumaric and citric acids were detected in $\mathrm{O}_{3}$ treatment. In this sense, it is worth noting that the results showed different degradation routes for the treatments studied (Scheme 1). 
Table 3

Summary of all products detected in the degradation studies of AY1 dye.

\begin{tabular}{|c|c|c|c|c|c|}
\hline Compound & $t_{\mathrm{R}} / \mathrm{min}$ & Proposed structures & {$[\mathrm{M}-\mathrm{H}]^{-} m / z^{\mathrm{b}}$} & Fragment ion (MS/MS) $\mathrm{m} / \mathrm{z}$ & Treatment detected \\
\hline Acid Yellow 1 & 4.08 & - & 313 & $233,296,173$ & $\mathrm{O}_{3}, \mathrm{PEC}, \mathrm{O}_{3}+\mathrm{PEC}$ \\
\hline Product $1^{\text {a }}$ & 3.65 & & 329 & $283,267,237$ & $\mathrm{O}_{3}, \mathrm{PEC}, \mathrm{O}_{3}+\mathrm{PEC}$ \\
\hline Product 2 & 6.90 & Not identified & 243 & $170,156,147,80$ & $\mathrm{O}_{3}, \mathrm{PEC}, \mathrm{O}_{3}+\mathrm{PEC}$ \\
\hline Product 3 & 1.77 & Not identified & 229 & $185,121,93,81$ & $\mathrm{O}_{3}, \mathrm{O}_{3}+\mathrm{PEC}$ \\
\hline Product 4 & 5.29 & Not identified & 225 & $161,117,80$ & $\mathrm{PEC}, \mathrm{O}_{3}+\mathrm{PEC}$ \\
\hline Malonic acid & 1.85 & - & 103 & 59,41 & $\mathrm{PEC}, \mathrm{O}_{3}+\mathrm{PEC}$ \\
\hline Citric acid & 1.87 & - & 191 & 111,87 & $\mathrm{O}_{3}, \mathrm{PEC}, \mathrm{O}_{3}+\mathrm{PEC}$ \\
\hline Fumaric acid & 2.38 & - & 115 & 71,43 & $\mathrm{O}_{3}, \mathrm{PEC}, \mathrm{O}_{3}+\mathrm{PEC}$ \\
\hline Tartaric acid & 1.62 & - & 149 & 87,73 & $\mathrm{PEC}, \mathrm{O}_{3}+\mathrm{PEC}$ \\
\hline
\end{tabular}

a Chemical structure with $\mathrm{OH}$ in undefined position in the aromatic ring.

b Detected in negative mode with $z=1$.

Other experiments performed using different potential for ionization did not show any product remaining. Furthermore, for all the intermediates analyzed it was also observed that following 60 min of treatment, all the compounds were completely eliminated from the samples. Table 3 summarizes all the products detected.

\section{Conclusions}

Our findings show for the first time that the combination of photoelectrocatalysis using $\mathrm{TiO}_{2}$ NTs electrode and ozonation $\left(\mathrm{O}_{3}+\mathrm{PEC}\right)$ is a powerful system capable of promoting a higher degradation and a higher mineralization of organic compounds even operating in high colorful effluents. The main drawback of the photoelectrocatalytic treatment lies in its low rate of compounds degradation in high concentrated effluents which can be successfully circumvented with its combination with ozonation which is efficient in color removal though lacks the ability to mineralize the dye. Photocatalytic ozonation $\left(\mathrm{O}_{3}+\mathrm{PC}\right)$ is a well-established technique in the literature, but under an applied voltage $\left(\mathrm{O}_{3}+\mathrm{PEC}\right)$ it was possible to reach an almost 2 times higher decolorization rate of AY1 dye, a total mineralization within a much shorter time and lower electrical energy cost. The efficiency of $\mathrm{O}_{3}+\mathrm{PEC}$ treatment is affected by the AY1 initial concentration and $\mathrm{pH}$, though it has been shown to work in a wide range of concentrations and in all the pHs tested. By increasing the ozone flow, it was possible to obtain a total mineralization of $100 \mathrm{ppm}$ AY1 dye in only $30 \mathrm{~min}$ and lower energy costs. Thus, the photoelectrocatalytic ozonation is a new approach among the AOPs, which can be a great alternative for the development of efficient and cost-effective methods of water treatment.

\section{Acknowledgements}

The authors would like to express their gratitude and indebtedness for the financial support provided by the Brazilian funding agencies FAPESP (process 2014/03679-7; 2011/23128-7 and 2008/10449-7), CAPES and CNPq. FEG-SEM facilities were provided by LMA-IQ and X-ray diffraction measurements by GFQM-IQ

\section{References}

[1] R. Daghrir, P. Drogui, D. Robert, J. Photochem. Photobiol. A: Chem. 238 (2012) 41-52.

[2] H. Zhang, G. Chen, D.W. Bahnemann, J. Mater. Chem. 19 (2009) 5089-5121.

[3] G.G. Bessegato, T.T. Guaraldo, M.V.B. Zanoni, Modern Electrochemical Methods in Nano, Surface and Corrosion Science, in: M. Aliofkhazraei (Ed.), InTech, 2014, pp. 271-319.

[4] C.E. Patrick, F. Giustino, Adv. Funct. Mater. 21 (2011) 4663-4667.

[5] M.V.B. Zanoni, T. Guaraldo, ECS Trans. 50 (2013) 63-70.

[6] M. Ni, M.K.H. Leung, D.Y.C. Leung, K. Sumathy, Renew. Sustain. Energy Rev. 11 (2007) 401-425.

[7] R.A.G. de Oliveira, M.V.B. Zanoni, Electroanalysis 25 (2013) 2507-2514

[8] T.J. LaTempa, S. Rani, N. Bao, C.A. Grimes, Nanoscale 4 (2012) 2245-2250.

[9] G.G. Bessegato, J.C. Cardoso, M.V.B. Zanoni, Catal. Today 240 (2014) 100-106.

[10] J.C. Cardoso, T.M. Lizier, M.V.B. Zanoni, Appl. Catal. B: Environ. 99 (2010) 96-102.

[11] I. Paramasivam, H. Jha, N. Liu, P. Schmuki, Small 8 (2012) 3073-3103.

[12] J. Georgieva, E. Valova, S. Armyanov, N. Philippidis, I. Poulios, S. Sotiropoulos, J. Hazard. Mater. 211 (2012) 30-46.

[13] T.A. Egerton, J. Chem. Technol. Biotechnol. 86 (2011) 1024-1031.

[14] T.E. Agustina, H.M. Ang, V.K. Vareek, J. Photochem. Photobiol. C: Photochem. Rev. 6 (2005) 264-273.

[15] L. Sánchez, J. Peral, X. Domènech, Appl. Catal. B: Environ. 19 (1998) 59-65.

[16] J. Nawrocki, B. Kasprzyk-Hordern, Appl. Catal. B: Environ. 99 (2010) 27-42.

[17] F. Parrino, G. Camera-Roda, V. Loddo, G. Palmisano, V. Augugliaro, Water Res. 50 (2014) 189-199.

[18] U. Cernigoj, U.L. Stangar, J. Jirkovský, J. Hazard. Mater. 177 (2010) 399-406.

[19] K. Rajeshwar, M.E. Osugi, W. Chanmanee, C.R. Chenthamarakshan, M.V.B. Zanoni, P. Kajitvichyanukul, R. Krishnan-Ayer, J. Photochem. Photobiol. C: Photochem. Rev. 9 (2008) 171-192.

[20] S. Wang, F. Shiraishi, K. Nakano, Chem. Eng. J. 87 (2002) 261-271.

[21] K. Rajeshwar, Encyclopedia of Electrochemistry, in: A.J. Bard, M. Stratmann, S. Licht (Eds.), Wiley-VCH Verlag GmbH \& Co., 2007, pp. 1-54.

[22] D. Tomova, V. Iliev, S. Rakovsky, M. Anachkov, A. Eliyas, G.L. Puma, J. Photochem. Photobiol. A: Chem. 231 (2012) 1-8.

[23] Z. Zsilák, E. Szabó-Bárdos, O. Fónagy, O. Horváth, K. Horváth, P. Hajós, Catal. Today 230 (2014) 55-60.

[24] G. Liao, D. Zhu, L. Li, B. Lan, J. Hazard. Mater. 280 (2014) 531-535.

[25] J.R. Bolton, K.G. Bircher, W. Tumas, C.A. Tolman, Pure Appl. Chem. 73 (2001) 627-637.

[26] M. Mehrjouei, S. Müller, D. Möller, Chem. Eng. J. 248 (2014) 184-190. 